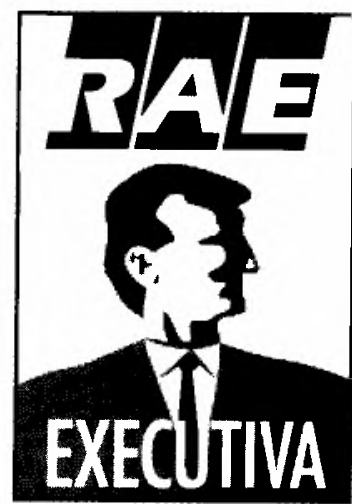

\title{
A BUSCA DA COMPETITIVIDADE NAS EMPRESAS
}

*Ricardo Motta

\section{Análise do atual ambiente competitivo e as estratégias que devem ser adotadas pelas empresas para obterem sucesso.}

\section{The current competitive environment and the key strategies to be} implemented by the companies to succeed.

PALAVRAS-ChAVE:

Competitividade, processos do negócio, corporação hori. zontal, globalizaçāo, administração por processos, alianças estratégicas, estratégla.

\section{KEY WORDS:}

Competitiveness, business process, horizontal corporation, globalization, process management, strategic alliances, strategies.
Estamos passando por um período de profundas transformações tanto no cenário econômico quanto no político, no social, no empresarial e no cultural. Enfim, estamos vivendo em uma época de mudanças que, embora sem padrões, dáse em um ambiente de evolução e desenvolvimento bastante acelerado.
No mundo específico dos negócios, notamos não apenas novas oportunidades, mas também uma mudança nas formas de planejamento e realização de negócios, de utilização de recursos e de atendimento e relacionamento com clientes, fornecedores, funcionários, acionistas e ainda com a comunidade. Na era da competitividade

*Gerente de Programas de Qualidade da IBM/Brasil.

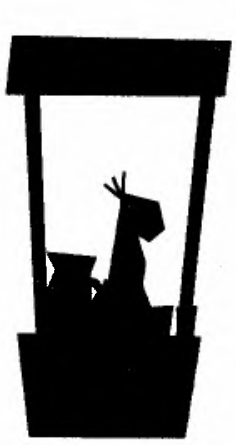

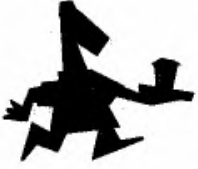

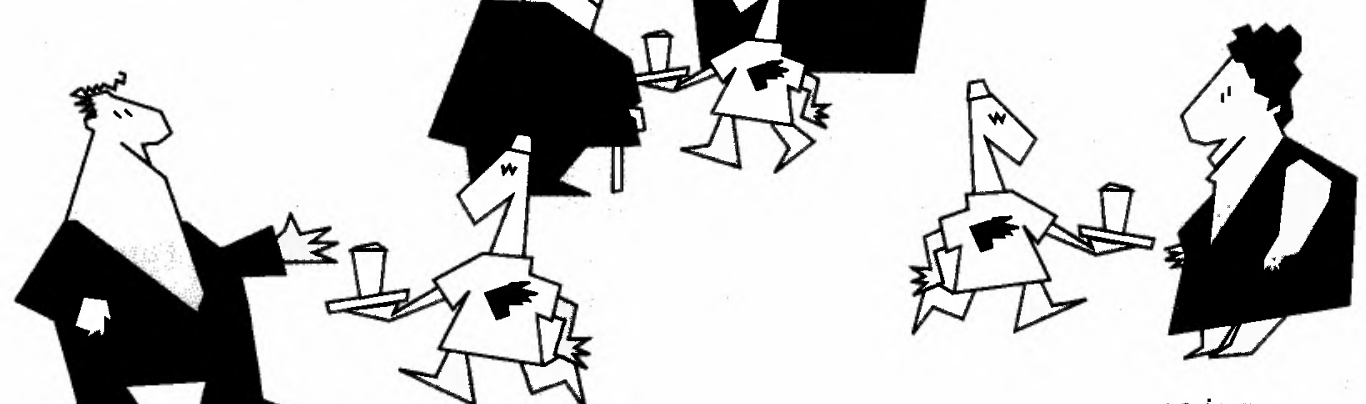

Arines 
global, o grande desafio das empresas está centrado na capacidade de busca de novas tecnologias, novos mercados e novos métodos de gerenciamento ou do redesenho dos processos de negócio e de integração total das cadeias de valor da empresa, clientes e fornecedores.

As bases para a competição têm mudado drasticamente nos anos 90 . O que era considerado inovador e criativo constituíase em base para a obtenção de vantagens competitivas na década de 80 , como, por exemplo, qualidade e custo baixo. Hoje, isso simplesmente é visto como requisito mínimo para se penetrar até mesmo em segmentos de mercados diferentes. Atualmente, năo é mais possivel desenvolver e comercializar um produto somente para o mercado de origem da empresa. O espectro da concorrência estende-se por todo o mundo, solicitando-nos a pensar globalmente, a obter ecomomias de escala mundial. Um exemplo da velocidade do processo de globalização é o número de chamadas telefônicas internacionais nos EUA, tanto daquelas efetuadas para fora do país como no sentido inverso, que simplesmente dobrou no período de 1988 a $1991^{1}$. Os investimentos americanos feito fora dos EUA aumentaram $35 \%$, para US $\$ 776$ bilhões, de 1987 a 1992.

As mudanças que estão ocorrendo atualmente não são meras tendências mas sim transformações radicais guiadas pela globalização dos mercados, tais como o uso cada vez maior da tecnologia da informação, como ilustra o gráfico 1, e de redes de computadores ligando o mundo todo. Além disso, as empresas têm promovido também uma reorganização estrutural, por meio do achatamento das suas estruturas hierárquicas. Como conseqüência dessa transformação está nascendo uma nova economia da era da informação, cujas fontes de riqueza são o conhecimento e o poder da comunicação, diferentemente, por exemplo, da importância que era dada aos recursos naturais e ao trabalho físico.

A comercialização dos pro- dutos e serviços em âmbito global demandará um amplo investimento em sistemas de informação. A eliminação de níveis hierárquicos será decorrente dessa concepção, já que a informação estará disponível cm tempo real, via modem, em qualquer local, em qualquer momento. Todos os funcionários na empresa terão informações $\mathrm{em}$ nível suficiente para conhecê-la tão bem quanto o seu presidente.

Para ser competitiva, a empresa terá que assimilar muito bem o significado da expressão flexibilidade. Diante de mudança no mercado, ela deverá ser capaz de reconfigurar-se anual, mensal ou até mesmo diariamente. Para tornar possível esse tipo de agilidade nas empresas, seus líderes estão enfatizando o rápido desenvolvimento de produtos e serviços, sistemas flexíveis e adaptáveis de produção e incentivos para o trabalho em equipe.

As empresas de sucesso adotarão estratégias muito mais amplas e integradas $c$ centrarão esforços em processos de melhoria que irăo afetar a cadeia de valor ${ }^{2}$ como um todo. Scrá necessário redefinir as relaçóes entre fornecedores, distribuidores $\mathrm{c}$ clientes, buscando o desenvolvimento de uma parceria ao longo de toda a cadeia de valor, que inclui a estruturaçāo conjunta de uma estratégia competitiva, com benefícios claros para todos. Essas cmpresas se anteciparão às necessidades dos seus clien-
1. WELCOME to true revolution. Fortune, New York, $v$ 128, n. 15 , Dec. 1993, p. 328.

2. PORTER, Michel E. Vantagem competitiva: criando $e$ sustentando desempenho superior. Rio de Janeiro: Campus, 1989.

\section{Gráfico 1}

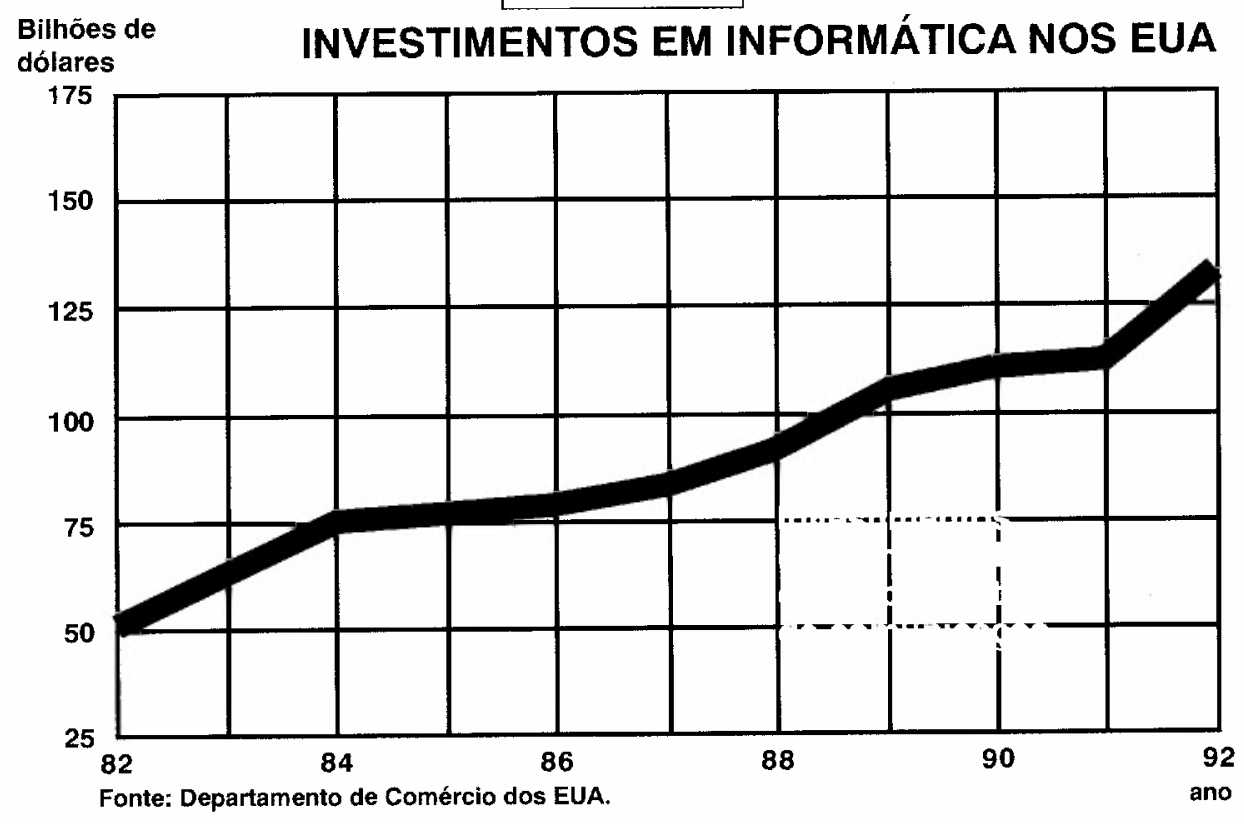

C 1995, Revista de Administração de Empresas / EAESP / FGV, São Paulo, Brasil. 
tes, devendo, por isso, enxergar além do horizonte do negócio atual, a fim de até mesmo influenciar fatores ambientais externos $\mathrm{c}$ fora do seu controle direto.

O mercado demanda um novo foco de melhoria que supera a eficiência e a eficácia. Até recentemente, a melhoria da competiçáo global de uma empresa ocorria por meio de ações localizadas, específicas de suas áreas funcionais internas, gerando açōes isoladas que quase sempre nāo produziam resultados claramente percebidos pelos clientes. Esse enfoque limitado para testar problemas nāo lhe permitia fazer uso de todo o potencial de direcionamento das ações para aquele que é o objetivo principal de qualquer empresa, ou seja, atender ou

0 que era considerado inovador $e$ criativo constituía-se em base para a obtenção de vantagens competitivas na década de $\mathbf{8 0}$, como, por exemplo, qualidade e custo baixo. Hoje, isso simplesmente é visto como requisito mínimo para se penetrar até mesmo em segmentos de mercados diferentes. até mesmo superar necessidades e expectativas dos clientes.

As novas ferramentas $\mathrm{e}$ técnicas para o ganho de vantagem competitiva oferecem à companhia enfoques que superam as barreiras funcionais, utilizando a sinergia de sua cadeia de valor como um todo. $\mathrm{O}$ objetivo principal está no entendimento dos principais impulsionadores do desempenho e do custo, examinados de forma holística por toda aquela cadeia.

Outro fator importante de competividade das empresas em busca de novos mercados está na formação de alianças econômicas globais. A estratégia que as empresas adotam nessa área possui implicações significativas na sua habilidade de buscar e de manter a qualidade de seus produtos e serviços.

Nesse caso, a assimilação de necessidades e expectativas dos clientes, dos ambientes de negócios e das diferenças culturais são fatores críticos de sucesso no gerenciamento de empresas inseridas em negócios globalmente cada vez mais dispersos.

O maior desafio das empresas, que atuam em mercados globais multiculturais, é ajustar seus enfoques e estratégias às necessidades individuais dos mercados sem perder de vista a missão da organização.
Assim, alianças estratégicas com parceiros inseridos em mercados distantes, com excclente nível de conhecimento e poder de comunicaçāo, alćm de compreensāo das necessidades específicas desses mercados, tornam-se cruciais para o sucesso global da empresa.

E muito importante que a empresa conheça claramente as forças que a cercam, para poder, após análise detalhada dessas forças, escolher efetivamente a sua cstratégia competitiva.

As regras da concorrência que determinam a atratividade do segmento de mercado na qual a cmpresa está inserida tal como em qualquer indústria, scja ela local ou multinacional, produzindo um produto ou um serviço - estão definidas nestas cinco forças competitivas ${ }^{3}$ : a entrada de novos concorrentes, a ameaça de produtos substitulos, o poder de negociação dos compradores, o poder de negociação dos fornecedores e a rivalidade dos concorrentes.

Essas forças determinam a rentabilidade da indústria porque influenciam definitivamente os seus custos, os preços e o investimento necessário $\mathrm{cm}$ um dado segmento. Assim, o entendimento das forças que a cercam vai permitir à empresa escolher efetivamente a sua estratégia competitiva. Essa metodologia permite que uma empresa perceba a complexidade e aponte os fatores críticos de sucesso frente à sua concorrência, além da identificação de inovações estratégicas para a melhoria de sua rentabilidade.

O conhecimento da base da concorrência permitirá, entāo, a determinação da vantagem competitiva a ser adotada: baixo custo ou diferenciação. Essas vantagens resultam de uma melhor habilidade da empresa, comparada com a dos seus concorrentes, em lidar com estas cinco forças. Esses dois tipos básicos de vantagem levam a empresa a adotar uma destas três estratégias competitivas: de liderança de custos, de diferenciação ou de enfoque. Esta última pode ser de enfoque no custo ou na diferenciação. As duas primeiras buscam a vantagem competitiva em um limite amplo de segmentos industriais, en- análise das indústrias e da concorrência. Rio de Janeiro: Campus, 1991. 
quanto a estratégia do enfoque visa a uma vantagem de custo ou a uma diferenciação em segmento de mercado específico.

Dado o papel fundamental da vantagem competitiva, que oferece valor superior aos clientes, resultando em desempenho igualmente superior, a principal peça no processo de planejamento estratégico da empresa deve ser sua estratégia genérica. Esta especifica o método primordial para a vantagem competitiva que a $\mathrm{cm}$ presa está buscando e fornece o contexto para a tomada de açōes $\mathrm{em}$ cada área funcional.

Neste novo cenário de negócios, a capacidade de transformar uma estratégia $\mathrm{cm}$ algo que possa ser executado com sucesso torna-se tarefa considerável. A idéia é incorporar cssa estratégia sob uma única visão, permitindo a tomada de decisões coerentes entre si, e estabelecer novo fundamento competitivo, focalizando esforços e direcionando as açôes a um objetivo comum. Essa estratégia também é incorporada sob a forma de missão, mas isso só não é suficiente, pois a estratégia deve ser traduzida em uma ação clara, com fatores críticos de sucesso definidos. Esses fatores definem o que é necessário para o alcance da missão $c$, conseqüentemente, para a obtenção das vantagens competitivas planejadas.

A eliminação de barreiras dentro de uma organização funcional e a visualização da empresa como um todo permite um maior inter-relacionamento dentro da cadeia de valor, por meio do conceito de processo $^{4}$ de negócio. Processos de negócio são os meios pelos quais uma empresa conduz seus negócios. Ao se centrar nesses processos, a empresa estará trabalhando com todas as dimensōes complexas do seu negócio e poderá usar, não mais de forma isolada, todos os seus esforços para adquirir as vantagens competitivas. Para a empresa, alguns dos benefícios advindos desses processos são ${ }^{\overline{5}}$ :

habilita a organização a ter seu foco direcionado aos clientes; permite à organização antecipar e controlar mudanças;

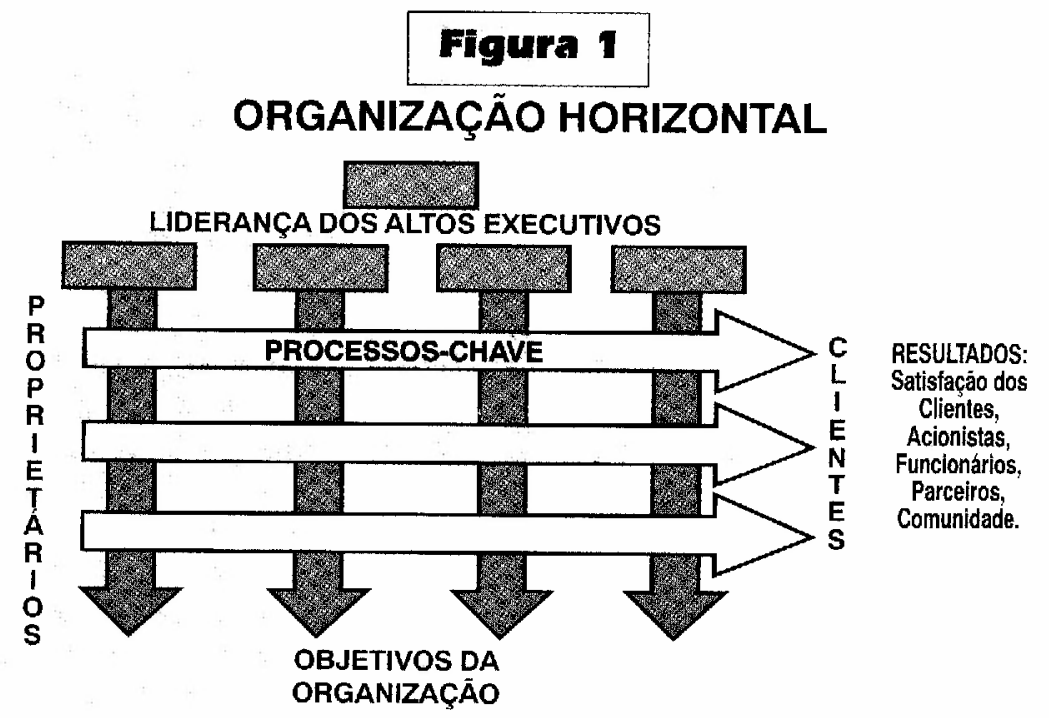

provê meios de efetivar, mais rapidamente, mudanças complexas; auxilia a organização a gerenciar efetivamente seus inter-relacionamentos; provê uma visão sistêmica das atividades da organização;

mantém o foco no processo; previne a ocorrência de erros; auxilia a organização a entender melhor a sua cadeia de valor;

desenvolve um sistema de avaliação completo para as áreas de negócios.

Alguns exemplos típicos de processos de negócio são: gerência de mercado, comercialização, satisfação de clientes, faturamento, compras, análise financeira, desenvolvimento de novos produtos, produção, gestão da qualidade, desenvolvimento de recursos humanos, dentre outros.

Nos tempos em que os negócios eram mais facilmente previsíveis e estáveis, as empresas organizavam-se verticalmente para obter vantagem dos recursos especializados, indispensáveis. Todos tinham um lugar e todos entendiam sua "micro" tarefa dentro da organização; o poder de decisão estava visivelmente no topo. Por outro lado, com o aumento da complexidade interfuncional, ficou cada vez mais difícil para cada membro da organização entender a missâo da empresa como um todo e como relacionar essa missão com seu trabalho.

A competição global e a alta velocidade das mudanças tecnológicas têm forçado a revisāo de estruturas organizacionais ${ }^{6}$,
4. Processo é uma organização de pessoas, equipamentos, procedimentos, informações, energia e materiais em atividades de trabalho logicamente relacionados e que agregam valor para o cliente com o objetivo de produzir resultados específicos.

5. MARQUES, Geraldo Lúcio. Além da qualidade total: a reengenharia de processos e a transformação do negócio. In: A era da competitividade global. Apostila de Seminário Executivo, Rio de Janeiro, 1992.

6. THE HORIZONTAL CORPOration. Business Week, New York, Dec. 20, 1993, p. 44-9. 
rumo à corporação horizontal. Com isso, todos estão voltados ao negócio principal da empresa, trabalhando nos processos do negócio, por meio de uma administração por processos.

Como demonstrado na figura 1 , a corporação horizontal, é um novo modelo organizacional, organizado por processos e não por tarefas. Cada processo possui um proprietário e objetivos de desempenho específicos. A hierarquia é, por definição, achatada, com grande uso de equipes de trabalho auto-sustentadas e gerenciadas. A organização é voltada para o cliente; a satisfaçâo deste é a medida primária do desempenho da empresa. Os lucros virão como consequêencia da satisfação dos clientes.

Os contatos com os clientes e fornecedores devem ser maximizados e, finalmente, os funcionários devem ter o máximo de informaçôes compartilhado, além do treinamento necessário para que possam tomar suas próprias decisões.

\section{FORNECENDO VALOR SUPERIOR AOS CLIENTES}

Os processos de negócio devem ser redesenhados levando-se em conta aspectos de custo e valor para o cliente. $O$ valor total percebido é definido como aquele do benefício do produto menos o do preço percebido. O cliente percebe valor no produto vendido se o valor do benefício for maior que aquele do preço.

Para que a empresa seja competitiva, o valor percebido deve ser positivo. Se o cliente não perceber valor no produto da empresa, esta torna-se uma séria candidata a deixar o mercado.

Alguns atributos de valor para o cliente, que devem ser considerados no processo de negócio, são qualidade, confiabilidade, conveniência, praticidade, beleza, status, garantia, dentre outros.

A vantagem competitiva surge fundamentalmente do valor que uma empresa tem ao criar condições para seus compradores. Esta vantagem pode tomar a forma de preços inferiores aos da concorrência, por meio de benefícios equivalentes, ou de fornecimento de benefícios únicos, que mais do que compensam um preço-prêmio.

Por meio da cadeia de valores de uma empresa podemos identificar e entender, de maneira sistemática, as fontes potenciais de acréscimo de valor ao cliente.

\section{A EMPRESA COMPETITIVA}

O conceito moderno de empresas competitivas abrange uma série de características-chave, que certamente são fundamentais para a sustentação de vantagens competitivas globais. São elas:

- orientação global para a satisfação dos clientes/consumidores, por meio do entendimento de suas necessidades e expectativas, atuais e futuras, suas preferências, seu conceito de valor percebido, com o objetivo de sempre se antecipar aos seus desejos, superando suas expectativas;

- ter vantagem competitiva no mercado em que atua, oferecendo produtos e serviços com valor superior ao oferecido por seus concorrentes;

- garantir que a noção de valor superior para o cliente esteja difundida, integrada e disseminada em todas as atividades da cadeia de valor da empresa e dos distribuidores;

- ter o conceito de lucro como conseqüência da orientação para o mercado, ou seja, satisfação dos clientes.

Entendendo seus processos, os escopos da competição global, o uso da tecnologia da informação e suas possibilidades, o uso de redes computacionais e a horizontalização da empresa, por meio de uma liderança forte dos altos executivos, as organizaçōes estarão prontas para atingirem vantagens competitivas durante a década de 90 e nas seguintes.

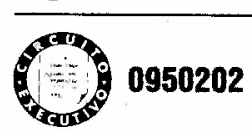

